\title{
Dissipation Pattern of Profenophos on Cabbage (Brassica oleracea var. Capitata)
}

\author{
Anugu Anil Reddy*, Shashi Vemuri, CH.S. Rao and A. Uma Rajashekhar \\ Ainp on Pesticide Residues, Eei Premises, Rajendra Nagar, Hyderabad-500 030, A.P. India \\ *Corresponding author
}

\author{
A B S T R A C T
}

\section{Ke y w o r d s \\ Insecticides, \\ Plutella xylostella, Initial deposit, \\ Efficacy, \\ Dissipation and Half-life. \\ Article Info \\ Accepted: \\ 17 May 2017 \\ Available Online: \\ 10 June 2017}

An experiment was conducted during kharif, 2012 to evaluate the efficacy of seven insecticides viz., emamectin benzoate $5 \mathrm{SG}$ at $11 \mathrm{~g}$ a.i.ha ${ }^{-1}$, emamectin benzoate $5 \mathrm{SG}$ at $22 \mathrm{~g}$ a.i.ha ${ }^{-1}$, profenophos $50 \mathrm{EC}$ at $500 \mathrm{~g}$ a.i.ha ${ }^{-1}$, profenophos 50 $\mathrm{EC}$ at $1000 \mathrm{~g}$ a.i.ha ${ }^{-1}$, spinosad $45 \mathrm{SC}$ at $100 \mathrm{~g}$ a.i.ha ${ }^{-1}$, bifenthrin $10 \mathrm{EC}$ at $100 \mathrm{~g}$ a.i.ha ${ }^{-1}$ and Bacillus thuringiensis at $5 \mathrm{WP}$ at $25 \mathrm{~g}^{\text {a.i.ha }}{ }^{-1}$ against DBM (Plutella xylostella) on cabbage of which profenophos $50 \mathrm{EC}\left(1000 \mathrm{~g}\right.$ a.i.ha $\left.{ }^{-1}\right)$, applied twice as foliar spray was found to be most effective in controlling the $P$. xylostella for which the dissipation studies were conducted. The dissipation pattern of profenophos $50 \mathrm{EC}\left(1000 \mathrm{~g}\right.$ a.i.ha $\left.{ }^{-1}\right)$ was studied collecting samples at regular intervals i.e. $0,1,3,5,7,10,15$ and 20 days after last spray and analyzed. The initial deposits of $0.99 \mathrm{mg} \mathrm{kg} \mathrm{m}^{-1}$ profenophos recorded at 2 hours after last spray dissipated to $0.85,0.82,0.16$ and $0.07 \mathrm{mg} \mathrm{kg-1}$ by $1,3,5$ and 7 days after last spray, respectively and below determination level (BDL) by 10th day.

\section{Introduction}

Cabbage (Brassica oleracea var. capitata L.) is the second important cruciferous vegetable crop in the world. In India, it is cultivated in an area of $0.369 \mathrm{~m}$ ha with an average annual production of $7.949 \mathrm{~m}$ MT and productivity of $21.5 \mathrm{MT} \mathrm{ha}^{-1}$. The major cabbage producing states are Maharashtra, Bihar, Karnataka, Orissa, West Bengal and Andhra Pradesh, whereas West Bengal ranks first both in area and production with $0.0753 \mathrm{~m}$ ha and $2.087 \mathrm{~m} \mathrm{MT}$, respectively (NHB 2011). It contains adequate quantities of vitamins A, B and $\mathrm{C}$ and minerals phosphorus, potassium, calcium, sodium and iron (Nath et al., 1984). Though lack of quality seeds, improved cultivars, F1 hybrids and suitable production technology contribute partly to the lower yields, various other factors are responsible for low productivity among which damage by various insect pests starting from transplanting till harvest is most significant.

A host of insect pests viz., diamond back moth, [Plutella xylostella (L.)], cabbage leaf webber, [(Crociodolomia rinotalis (Zell.)], tobacco caterpillar, [(Spodoptera litura (Fab.)] and mustard aphid, [Brevecornyae brassicae (L.)] etc., attack the crop, among these diamond back moth, [Plutella xylostella (L.)] is the most notorious and pernicious pest on cruciferous vegetables causing 52 percent loss in marketable produce (Krishna kumar et 
al., 1986), farmers apply pesticides 8 to 10 times to effectively control this pest. Indiscriminate use of pesticides leads to undesirable load of pesticide residues in marketable vegetables (Kumari et al., 2005) and cause severe ecological consequences like destruction of natural enemy fauna, effect on non-target organisms and directly effect in the form of residues. Hence studies were conducted for the efficacy of different insecticides used commonly and also to establish the dissipation pattern of relatively safer insecticides to fit in pest management strategy.

\section{Materials and Methods}

The experiment was laid out in a Randomized Block Design (RBD) with 8 treatments including untreated control replicated thrice with individual plot size of $20 \mathrm{~m} 2(5 \mathrm{mx} 4 \mathrm{~m})$ and the insecticides viz., emamectin benzoate $5 \mathrm{SG}$ at $11 \mathrm{~g}$ a.i.ha ${ }^{-1}$, emamectin benzoate 5 $\mathrm{SG}$ at $22 \mathrm{~g}$ a.i.ha ${ }^{-1}$, profenophos $50 \mathrm{EC}$ at 500 g a.i.ha ${ }^{-1}$, profenophos $50 \mathrm{EC}$ at $1000 \mathrm{~g}$ a.i.ha 1 , spinosad $45 \mathrm{SC}$ at $100 \mathrm{~g}$ a.i.ha ${ }^{-1}$, bifenthrin $10 \mathrm{EC}$ at $100 \mathrm{~g}$ a.i.ha ${ }^{-1}$ and Bacillus thuringiensis at $5 \mathrm{WP}$ at $25 \mathrm{~g}$ a.i.ha ${ }^{-1}$ on cabbage first at head initiation and the second spray ten days later to evaluate the efficacy against P. xylostella of which profenophos 50 EC at $1000 \mathrm{~g}$ a.i.ha ${ }^{-1}$ was the most effective and the dissipation studies were conducted for the same by collecting cabbage samples at regular intervals i.e. $0,1,3,5,7,10,15$ and 20 days after last spray in polythene bags and brought to the laboratory immediately for further sample processing in the laboratory as detailed here under.

\section{Results and Discussion}

Initial deposits of $0.99 \mathrm{mg} \mathrm{kg}^{-1}$, profenophos were detected at 2 hours after last spray, which dissipated to Below Determination Level (BDL) of $0.05 \mathrm{mg} \mathrm{kg}^{-1}$, by 10 th day after last spraying on cabbage. The initial deposits were dissipated to $0.85,0.82,0.16$ and $0.07 \mathrm{mg} \mathrm{kg}^{-1}$, by $1,3,5$ and 7 days after last spray, respectively. The dissipation pattern showed constant decrease of residues from first day to 7 th day. The residues dissipated by $14.14,17.17,83.84$ and $92.93 \%$ on 1, 3, 5and 7th day, respectively. The regression equation is $\mathrm{Y}=1.031+(-0.141) \mathrm{X}$ with R2 of 0.896. Maximum Residue Limit for profenophos in cabbage as per European

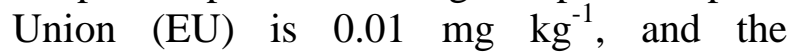
calculated 14.27 days based on dissipation pattern data. Hence, a safe waiting period is 15 days is recommended. Maximum Residue Limit for profenophos in cabbage as per Codex Alimentarius Commission (CAC) has not been set. The half-life of profenophos on cabbage was 4.91 days.

The present results are in agreement with the findings of Barba et al., (1987) who reported degradation of profenophos residues from 0.60 to 0.04 ppm by 7 days on globe artichokes.

The results are in the agreement with the findings of Malla Reddy (2003) who reported that, profenophos at $0.05 \%$ sprayed on cabbage heads, had very low initial deposits of $0.91 \mathrm{mg} \mathrm{kg}^{-1}$, i.e., less than the MRL value of $1.00 \mathrm{mg} \mathrm{kg}^{-1}$ with a waiting period of one day. The residues of profenophos $(0.05 \%)$ dissipated from cabbage heads to an extent of $93.40 \%$ in ten days after spraying. The removal of upper most layers on cabbage heads and subsequent water washings reduced the initial deposit of profenophos to an extent of $91.20 \%$. 


\section{Extraction and clean -up}

Cabbage heads $(5 \mathrm{~kg})$ were homogenized with robot coupe blixer and homogenized

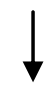

$15 \pm 0.1 \mathrm{~g}$ sample was taken in $50 \mathrm{ml}$ centrifuge tube

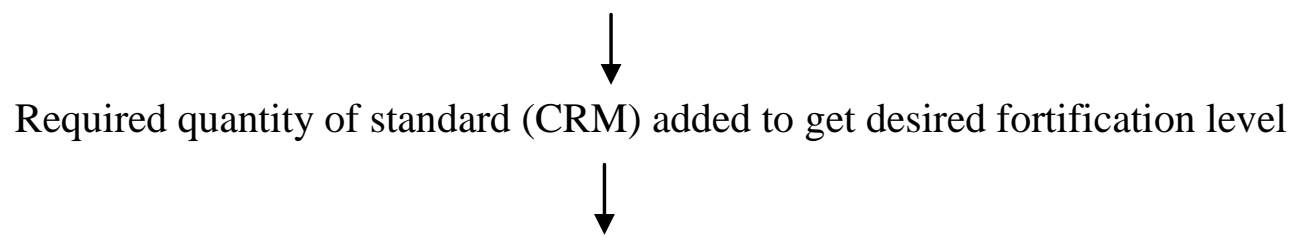

$30 \pm 0.1 \mathrm{ml}$ acetonitrile was added to the tube

The sample was homogenized at 14000-15000 rpm for 2-3 min

Using Heidolph silent crusher

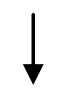

$3 \pm 0.1 \mathrm{~g}$ sodium chloride was added to tube and mixed by shaking gently

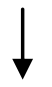

Centrifuged for $3 \mathrm{~min}$ at 2500-3000 rpm to separate the organic layer

The top organic layer of about $16 \mathrm{ml}$ was taken into the $50 \mathrm{ml}$ centrifuge tube

$9 \pm 0.1 \mathrm{~g}$ anhydrous sodium sulphate was added to remove the moisture content

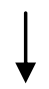

$8 \mathrm{ml}$ of extract was taken in to $15 \mathrm{ml}$ tube containing

$0.4 \pm 0.01 \mathrm{~g}$ PSA sorbent (for dispersive solid phase d-SPE cleanup) and

$1.2 \pm 0.01 \mathrm{gr}$ anhydrous magnesium sulphate

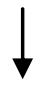

The sample tube was vertexed for $30 \mathrm{sec}$

Followed by centrifugation for $5 \mathrm{~min}$ at $2500-3000 \mathrm{rpm}$

The extract of about $2 \mathrm{ml}$ was transferred into test tubes and evaporated to dryness using turbovap with nitrogen gas and reconstituted with $1 \mathrm{ml}$-Hexane: Acetone (9:1) for GC analysis with ECD and TSD for profenophos analysis. 
Table.1 Dissipation of Profenophos (1000 g a.i.ha $\left.{ }^{-1}\right)$ in cabbage

\begin{tabular}{|c|c|c|c|c|c|}
\hline \multirow[b]{2}{*}{ Days after last spray } & \multicolumn{4}{|c|}{ Residues of profenophos $\left(\mathrm{mg} \mathrm{kg}^{-1}\right)$} & \multirow{2}{*}{$\begin{array}{c}\text { Dissipation } \\
\%\end{array}$} \\
\hline & R1 & $\mathbf{R} 2$ & $\mathbf{R 3}$ & Average & \\
\hline 0 & 1.05 & 0.95 & 0.97 & 0.99 & 0 \\
\hline 1 & 0.87 & 0.82 & 0.85 & 0.85 & 14.14 \\
\hline 3 & 0.80 & 0.72 & 0.96 & 0.82 & 17.17 \\
\hline 5 & 0.17 & 0.14 & 0.15 & 0.16 & 83.84 \\
\hline 7 & 0.08 & 0.07 & 0.06 & 0.07 & 92.93 \\
\hline 10 & BDL & BDL & BDL & BDL & 100 \\
\hline 15 & BDL & BDL & BDL & BDL & 100 \\
\hline 20 & BDL & BDL & BDL & BDL & 100 \\
\hline Regression equation & \multicolumn{5}{|c|}{$\mathrm{Y}=1.031+(-0.141) \mathrm{X}$} \\
\hline $\mathrm{R}^{2}$ & \multicolumn{5}{|c|}{0.896} \\
\hline Half-life & \multicolumn{5}{|c|}{4.91 days } \\
\hline $\begin{array}{l}\text { Safe waiting period } \\
\text { (As per EU MRL = } \\
0.01 \mathrm{mg} \mathrm{kg}^{-1} \text { ) }\end{array}$ & \multicolumn{5}{|c|}{15 days } \\
\hline
\end{tabular}

BDL: Below Determination Level $\left(0.05 \mathrm{mg} \mathrm{kg}^{-1}\right)$

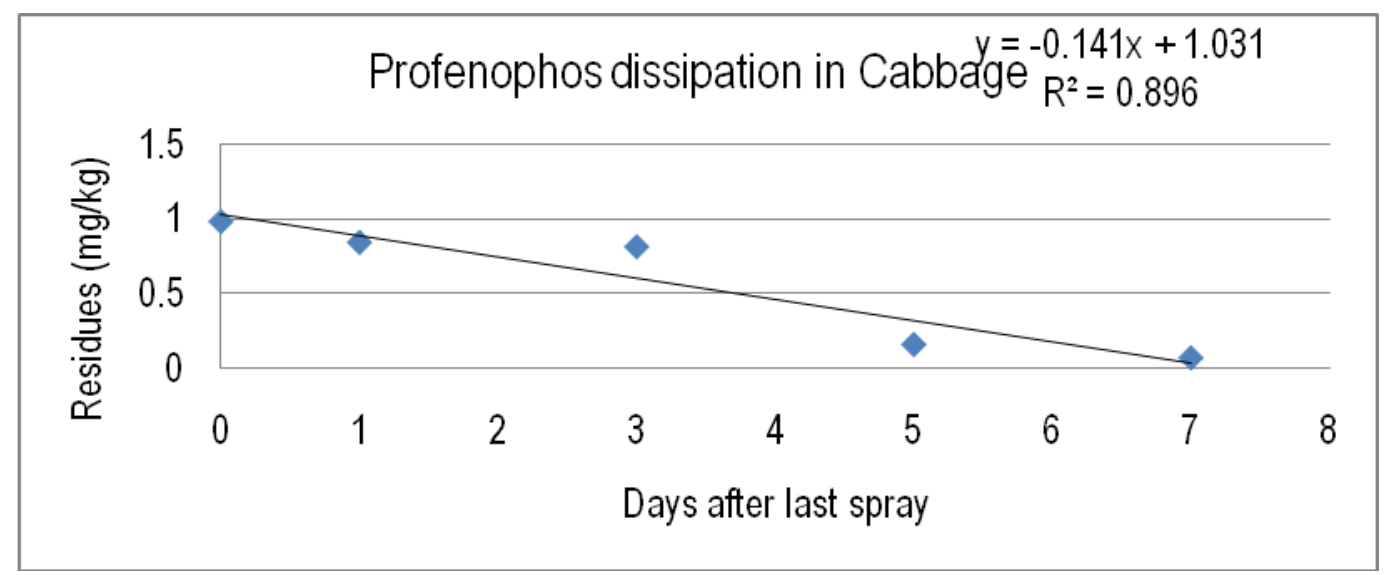

Standard sample

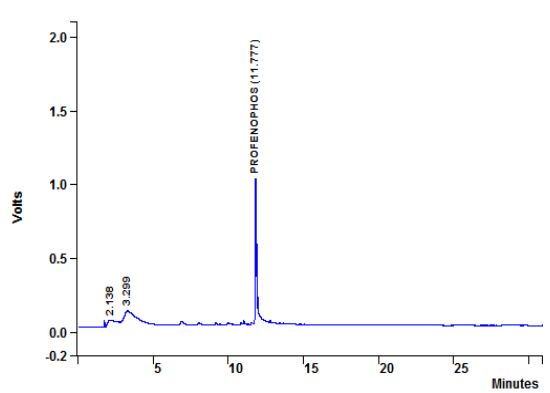

zero day sample

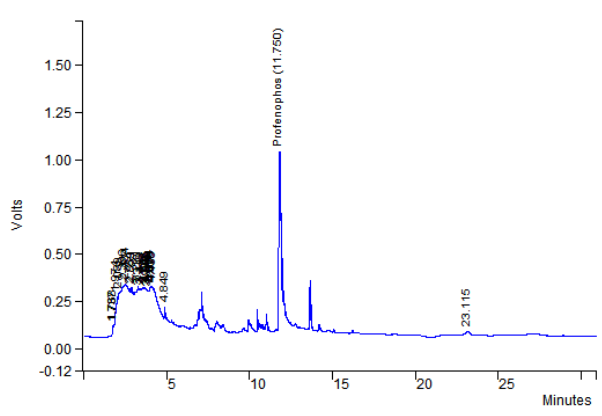


One day sample

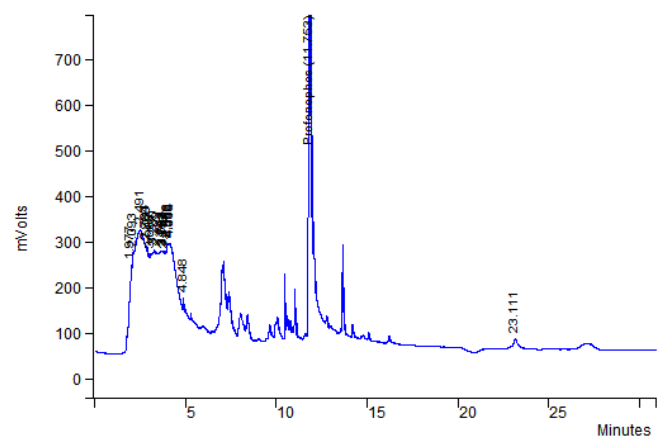

5 day sample

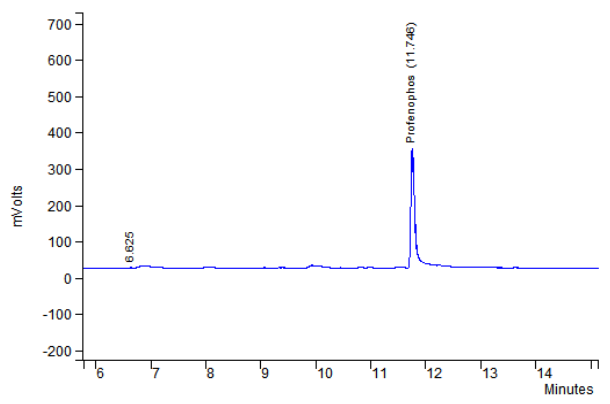

The results of the present studies are in agreement with the findings of Reddy et al., (2007) who studied the dissipation of profenofos $\left(0.1 \%\right.$ a.i.ha $\left.{ }^{-1}\right)$ on chillies sprayed at 15 days interval, starting from 45 days after transplanting and recorded initial deposits of profenophos $0.36 \mathrm{mg} \mathrm{kg}^{-1}$ after last spray which dissipated to $0.02 \mathrm{mg} \mathrm{kg}^{-1}$ by 30 days amounting to loss of $92.4 \%$ (Table 1).

Experimental results of Radwan et al., (2004) also showed a waiting period of 10 and 14 days after application of profenophos at $400 \mathrm{~g}$ a.i.ha ${ }^{-1}$ on green pepper and eggplant, respectively. Similarly, Sahoo et al., (2004) reported an initial deposit of $1.37 \mathrm{mg} \mathrm{kg}^{-1}$ following application of profenophos at $500 \mathrm{~g}$ a.i.ha ${ }^{-1}$ on tomato. These levels were reduced to below determination level (BDL) after 15 days of application.

In conclusion, the initial deposit of
3 day sample

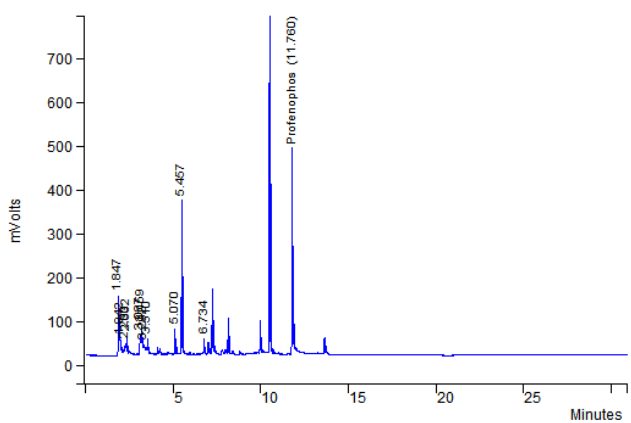

7 day sample

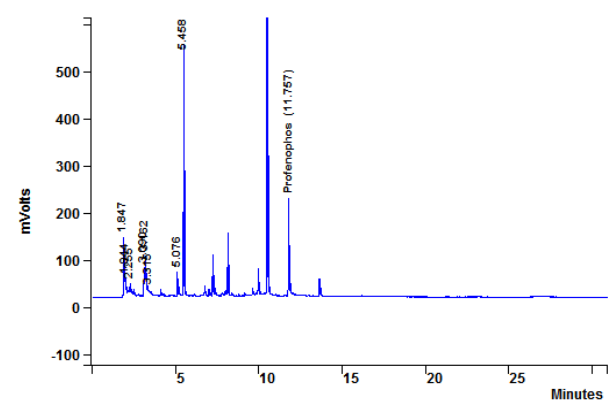

Profenophos when sprayed thrice at $0.05 \%$ during head formation stage was $0.99 \mathrm{mg} \mathrm{kg}^{-1}$. The waiting period for safe harvest of cabbage heads when sprayed Profenophos $0.05 \%$ thrice at head formation stage was 0.672 days.

\section{References}

Barba, A., Camara, M.A., Galindo, L. and Lopez Del-Hicron, N. 1987. Persistence of profenophos in artichokes. Revistade-Agron-Technologia -de-Alimendos, 27(3): 457-461.

Krishna kumar, N.K. Srinivas, K. Suman, C.L and Ramachander, P.R. 1986. Optimum control strategy of cabbage pests from a chemical control, Prog. Hort., 18: 104110.

Malla Reddy, K. 2003. Bio-efficacy and dissipation of certain insecticides on pests of cabbage. M.Sc (Ag.) Thesis. 
Acharya N G Ranga Agricultural University, Hyderabad, India.

National Horticultural Board. Annual report 2011. p. 184-187.

Radwan, M.A., Shiboob, M.H., AbuElamayem, M.M. and Abdel-Aal, A. 2004. Residues of pirimiphos-methyl and profenofos on green pepper and eggplant fruit and their effects on some quality properties. Emirates J. Agri. Sci., 16(1): 32-42.
Reddy, K.D. Reddy, K.N. Mahalingappa, P.B. 2007. Dissipation of fipronil and profenofos residues in chillies (Capsicum annum L.). Pesticide Res. J., 19(1): 106-107.

Sahoo, S.K., Kapoor, S.K and Singh, B. 2004. Estimation of flubendiamide residues of profenofos in/on tomato, Lycopersicon esculentum Mill. Bull. Environ. Contaminat. Toxicol., 72: 970-974.

\section{How to cite this article:}

Anugu Anil Reddy, Shashi Vemuri, Rao CH. S. and Uma Rajashekhar A. 2017. Dissipation pattern of Profenophos on cabbage (Brassica oleracea var. Capitata). Int.J.Curr.Microbiol.App.Sci. 6(6): 1115-1120. doi: https://doi.org/10.20546/ijcmas.2017.606.129 